This item was submitted to Loughborough's Research Repository by the author.

Items in Figshare are protected by copyright, with all rights reserved, unless otherwise indicated.

\title{
Biomarker assessment of tobacco smoking exposure and risk of dementia death: pooling of individual-participant data from 14 cohort studies
}

\section{PLEASE CITE THE PUBLISHED VERSION}

http://dx.doi.org/10.1136/jech-2017-209922

\section{PUBLISHER}

(c) The Authors. Published by BMJ Publishing Group

\section{VERSION}

AM (Accepted Manuscript)

\section{PUBLISHER STATEMENT}

This work is made available according to the conditions of the Creative Commons Attribution-NonCommercialNoDerivatives 4.0 International (CC BY-NC-ND 4.0) licence. Full details of this licence are available at: https://creativecommons.org/licenses/by-nc-nd/4.0/

\section{LICENCE}

CC BY-NC-ND 4.0

\section{REPOSITORY RECORD}

Batty, G. David, Martin J. Shipely, Elisabeth Kvaavik, Tom C. Russ, Mark Hamer, Emmanuel Stamatakis, and Mika Kivimaki. 2019. "Biomarker Assessment of Tobacco Smoking Exposure and Risk of Dementia Death: Pooling of Individual-participant Data from 14 Cohort Studies”. figshare. https://hdl.handle.net/2134/27966. 


\section{Journal of \\ Epidemiology \& \\ Community Health}

\section{Biomarker assessment of tobacco smoking exposure and risk of dementia death: pooling of individual-participant data from 14 cohort studies}

\begin{tabular}{|r|l|}
\hline Journal: & Journal of Epidemiology \& Community Health \\
\hline Manuscript ID & jech-2017-209922.R2 \\
\hline Article Type: & Short Report \\
\hline Date Submitted by the Author: & 22-Dec-2017 \\
\hline Complete List of Authors: & $\begin{array}{l}\text { Batty, David; University College London, Epidemiology and Public Health } \\
\text { Shipley, Martin; University College London, Epidemiology and Public Health } \\
\text { Kvaavik, Elisabeth; Norwegian Institute of Public Health, Department of } \\
\text { Drug Policy, } \\
\text { Russ, Tom; University of Edinburgh, Alzheimer Scotland Dementia } \\
\text { Research Centre } \\
\text { Hamer, Mark; Loughborough University, School of Sport, Exercise and } \\
\text { Health Sciences } \\
\text { Stamatakis, Emmanouil; University College London, Department of } \\
\text { Epidemiology and Public Health } \\
\text { Kivimaki, Mika; University College London, Department of Epidemiology \& } \\
\text { Public Health }\end{array}$ \\
\hline Keywords: & \begin{tabular}{l} 
SMOKING, DEMENTIA, Cohort studies \\
\hline
\end{tabular} \\
\hline
\end{tabular}




\section{Biomarker assessment of tobacco smoking exposure and risk of dementia death: pooling of individual-participant data from 14 cohort studies}

G. David Batty, DSc ${ }^{\text {a }}$ (E. david.batty@ucl.ac.uk)

Martin Shipley, MSc ${ }^{\mathrm{a}}$ (E. martin.shipley@ucl.ac.uk)

Elisabeth Kvaavik, PhD ${ }^{\mathrm{b}}$ (E. elisabeth.kvaavik@,fhi.no)

Tom Russ, PhD ${ }^{c}$ (E.t.c.russ@ed.ac.uk)

Mark Hamer, PhD ${ }^{\text {d }}$ (E. m.hamer@lboro.ac.uk)

Emmanouil Stamatakis, PhD ${ }^{\mathrm{a}}$ (E. emmanuel.stamatakis@sydney.edu.au)

Mika Kivimäki, $\mathrm{PhD}^{\mathrm{a}}$ (E. $\underline{\text { m.kivimaki@ucl.ac.uk })}$

${ }^{\mathrm{a} D e p a r t m e n t ~ o f ~ E p i d e m i o l o g y ~ a n d ~ P u b l i c ~ H e a l t h, ~ U n i v e r s i t y ~ C o l l e g e ~ L o n d o n, ~ L o n d o n, ~ U K ~}$

${ }^{b}$ Department of Drug Policy, Norwegian Institute of Public Health, Oslo, Norway

${ }^{\mathrm{c}}$ Alzheimer Scotland Dementia Research Centre, University of Edinburgh, Edinburgh, UK

${ }^{\mathrm{d}}$ School of Sport, Exercise and Health Sciences, Loughborough University, Loughborough, UK

Corresponding author: David Batty, Department of Epidemiology and Public Health, University College London, 1-19 Torrington Place, London, UK, WC1E 6BT.

Manuscript statistics: 1484 words, 215 word abstract, 16 references, 1 table, 1 supplemental table

Licence for Publication: The Corresponding Author has the right to grant on behalf of all authors and does grant on behalf of all authors, an exclusive licence (or non exclusive for government employees) on a worldwide basis to the BMJ Publishing Group Ltd to permit this article (if accepted) to be published in JECH and any other BMJPGL products and sublicences such use and exploit all subsidiary rights, as set out in our licence

(http://group.bmj.com/products/journals/instructions-for-authors/licence-forms).

Author contributions: Study concept and design: GDB; Acquisition and preparation of the dataset (including mortality linkage): ES; Statistical analysis: MS; Interpretation of the data: All authors; Drafting of the manuscript: GDB; Critical revision of the manuscript for important intellectual content: All authors. MS had full access to all of the data in the study and takes responsibility for the integrity of the data and the accuracy of the data analysis. All authors saw and agreed on the final manuscript as well as the decision to submit for publication.

Conflicts of Interest and Financial Disclosures: None to declare.

Acknowledgements: GDB is supported by the UK Medical Research Council (MRC) and the US National Institute on Aging; MS by the British Heart Foundation; MK by the UK MRC, NordForsk, and the Nordic Research Programme on Health and Welfare; and ES by a National Health and Medical Research Council (Australia) Senior Research Fellowship. The funders had no role in the design and conduct of the study; collection, management, analysis, and interpretation of the data; preparation, review, or approval of the manuscript; or the decision to submit the manuscript for publication.

Contributorship statement: GDB generated the idea for the study, developed the analytical plan, and wrote the manuscript. MS and MK developed the analytical plan. MS analysed the data. ES built the dataset. All authors commented on the first draft of the manuscript. 


\begin{abstract}
Background: While there is a suggestion that self-reported tobacco smoking may be a risk factor for dementia, to date, it has not been possible to explore the thresholds at which this exposure elevates risk. Accordingly, our aim was to relate cotinine, a biomarker of tobacco smoking, to risk of dementia death.

Methods: We pooled 14 prospective cohort studies that held data on cotinine (plasma or saliva), covariates, and death records.

Results: In the 33,032 study members (17,107 women) with salivary cotinine data, a mean duration of 8.3 years of follow-up gave rise to 135 deaths ascribed to dementia; while in 15,130 study members (7995 women) with plasma cotinine data, there were 119 dementia deaths during 14.3 years of mortality surveillance. After multiple adjustment, both plasma cotinine (hazard ratio per one standard deviation higher cotinine; $95 \%$ confidence interval: $1.29 ; 1.05,1.59$ ) and salivary cotinine $(1.10 ; 0.89,1.36)$ were positively related to dementia risk, with stronger effects for plasma. Conclusion: Our finding that plasma cotinine was related to an elevated risk of dementia death warrants testing in studies with measures of disease onset as opposed to just mortality.
\end{abstract}




\section{What is already known}

- In cohort studies, self-reported cigarette smoking reveals a positive relation with dementia risk.

- In the absence of objective measurement of this health behaviour, it has not been possible to explore the thresholds at which this exposure elevates dementia risk.

\section{What this paper adds}

- To the best of our knowledge, this is the first study to utilise objective (cotinine) data to examine the smoking-dementia link. 


\section{Introduction}

It is well documented that dementia is, and will remain for the foreseeable future, a global public health priority.(1) The fiscal, social and health consequences of dementia are profound.(1) In the absence of effective treatments, much research attention has focused on primary prevention via the identification of modifiable risk factors which may be associated with the occurrence of dementia, its progression, and prognosis.(2) Position statements and systematic reviews of the literature have suggested a role for selected nutritional factors, physical inactivity, certain somatic medical conditions, and cognitive training, although the evidence base, while voluminous, is inconclusive.(2)

Cigarette smoking is another plausible modifiable risk factor. Small scale, high resolution studies showing that smokers, relative to their non-smoking counterparts, have a greater degree of brain atrophy, and lower grey matter density in selected areas(3) has prompted a series of large, population-based investigations of the link between this health behaviour and dementia risk. While these generally show that cigarette smokers typically experience higher rates of future dementia,(3, 4) with the evidence being based exclusively on self-reported smoking data it has not been possible to explore the thresholds at which this exposure elevates risk. Utilising objective markers of exposure to direct and indirect cigarette smoking, such as cotinine, would circumvent this problem but we are unaware of any such studies. Accordingly, we carried out a pooling of raw data from 14 longitudinal studies with information on cotinine and dementia.

\section{Methods}

We pooled individual-level data from 14 independent, geographically-representative, methodologically near-identical surveys of individuals living in private households conducted between 1994 and 2008 in the UK.(4-7) Ethical approval for each survey was granted by local Research Ethics Committees, and study members provided informed consent. 


\section{Measurement of cotinine and covariates}

In 3 studies taking place before 1998 (Health Survey for England [HSE] 1994, 1996; and Scottish Health Survey [SHS] 1995) the assessment of cotinine was based on a sample of venous blood, whereas salivary cotinine was captured subsequently in 11 studies (HSE [1998-2004, 2007, 2008] and SHS [1996, 2003]). All cotinine assays were performed by the same laboratory using standard gas chromatographic methods with a lower detection limit of $0.1 \mathrm{ng} / \mathrm{ml} .(8)$ While plasma cotinine and salivary cotinine are strongly correlated, levels are typically higher in saliva to the extent that the two measures cannot be combined.(9) Our covariates of socioeconomic status, frequency of alcohol consumption, and longstanding illness were self-reported using standard protocols.

\section{Ascertainment of dementia}

Study members were linked to national cause of death registers until $15^{\text {th }}$ February 2011 for HSE or $31^{\text {st }}$ December 2009 for SHS. Dementia was denoted by any mention of death from this disorder on certificates, as identified using codes 290.0 to $290.4,294.9,331.0$ to 331.2 and 331.9 (for ICD-9) and codes F00, F01, F03, F09, G30 and G31 (for ICD-10). In a cohort of Scottish individuals participating in a memory clinic who had gerontologist-confirmed dementia, almost three quarters of those who subsequently died had dementia recorded on their death certificate.(10) This suggests the use of any mention of death from this disorder has sufficient validity for use in population-based studies.

\section{Data analyses}

We pooled the data for the 14 studies and fitted Cox proportional hazards models(11) to estimate hazard ratios with accompanying 95\% confidence intervals for the association between each of the two indicators of cotinine and dementia death rates. Initially, we adjusted hazard ratios for survey year, sex and age (linear and quadratic). Subsequently, the confounding variables of socioeconomic 
status, alcohol intake, and longstanding illness were added to the multivariable model. Throughout our analyses we used calendar period as the time scale. All analyses were computed using SAS (version 9.3).

\section{Results}

In the 33,032 study members $(17,107$ women) with salivary cotinine data, a mean duration of 8.3 years of follow-up gave rise to 135 deaths ascribed to dementia; while in 15,130 study members (7995 women) with plasma cotinine data, there were 119 dementia deaths during 14.3 years of mortality surveillance.

Both plasma cotinine and salivary cotinine were positively related to dementia risk, such that higher levels of exposure were associated with an elevated dementia rates (table 1). The magnitude of these associations were markedly greater for plasma cotinine, with statistical significance apparent in people with a level of $>200 \mathrm{ng} / \mathrm{ml}$ (vs. 0-1.0: age-, sex-, and study year-adjusted hazard ratio; 95\% confidence interval: $1.84 ; 1.02,3.33)$. While there was also a suggestion of a dose-response relationship across the plasma cotinine categories (p-value 0.02), active rather than passive smoking appeared to be generating this gradient. Controlling for covariates which included existing physical illness had little impact of the strength of these relationships. Adding self-reported cigarette smoking to the multivariable model, however, essentially eliminated the age- and sex-adjusted relationship between plasma cotinine and dementia (>200.0 vs. $0-1.0 \mathrm{ng} / \mathrm{ml}: 1.16 ; 0.45,3.00)$. By contrast, hazard ratio for current cigarette smoking remained elevated (vs. never smokers: 2.04; $0.83,5.05)$ even after adjustment for plasma cotinine, although statistical at conventional levels was not apparent.

In sub-group analyses, we explored the issue of reverse causality such that unmeasured dementia at baseline - there was no cognitive testing in our studies - may have led to an elevation in the 
prevalence of cigarette smoking, potentially due to the raised levels of psychological distress seen in people experiencing cognitive impairment.(12) To do so, we dropped dementia deaths within the first 5 years of mortality surveillance and repeated our analyses (Supplemental Table 1). With these exclusions $-24 / 119$ of the dementia deaths in the plasma cotinine analyses and 37/135 of the dementia deaths in the salivary cotinine analyses occurred in the first 5 years of follow-up - the trend and hazard ratios in the plasma cotinine categories has strengthened somewhat while the hazard ratios for salivary cotinine are essentially unchanged.

\section{Discussion}

The main finding of this pooling of individual participant data from 14 prospective cohort studies was that plasma cotinine levels were related to a higher dementia risk in a dose-response manner, while the association with salivary cotinine was much weaker. That adjustment for self-reported cigarette smoking eliminated the plasma cotinine-dementia association suggests that our assessment of plasma cotinine provides no additional value for the prediction of this disorder beyond selfreported smoking behaviour.

\section{Study strengths and limitations}

The present study has some strengths, including the use of a biomarker of tobacco smoking rather than self-report, and the near full coverage of study members for mortality surveillance. It is also not without its shortcomings. The short half-life of cotinine means that it does have limitations in capturing longer term exposure to smoking. While we have previously demonstrated that dementia death appears to be a valid indicator of dementia in population-based studies,(10) this health outcome does nonetheless combines disease incidence (aetiology) and survival from the disorder (prognosis). Having comprehensive data on dementia incidence, which is problematic to capture except via extensive cognitive testing, would have greater utility when investigating the risk factors for this disorder. Lastly, a low number of dementia deaths meant that we were not able to examine 
the association between passive smoking and dementia by exploring cotinine-dementia links in self-declared in non-smokers.

\section{Existing literature and potential mechanisms}

While there are, to the best of our knowledge, no studies relating a biomedical marker of exposure to tobacco smoke and dementia risk, several investigators have characterised self-reports of this health behaviour in the context of both active and passive smoking. As described, reviews of direct smoking generally reveal positive relationships with dementia risk.(2) In studies which attempt to capture second-hand smoking via self-report there is also evidence of an increased risk of dementia although at rates which, as expected, appear to be lower than those seen in active smokers.(13) In one of the few studies to have explored the link between biochemical markers of tobacco smoke and cognitive ability, itself a powerful risk factor for dementia, there was evidence that higher levels of salivary cotinine were associated with greater impairment.(14)

That the cotinine-dementia gradient was robust to adjustment for selected confounding factors raises the possibility that direct mechanisms may be generating this association. As indicated, imaging studies suggest that, compared with abstainers, smokers have a greater degree of brain atrophy, and lower grey matter density in selected areas.(3) Other potential explanations include the observation that smoking exposure has a deleterious influence on the cardiovascular system, including increased coagulation of blood platelets, decreased coronary flow velocity reserves, accelerated atheroma genesis, and endothelial dysfunction.(15) Endothelial dysfunction has been implicated in the reduced clearance of $\beta$-amyloid protein which is involved in the pathogenesis of Alzheimer's disease.(16)

In conclusion, our finding that plasma cotinine was related to an elevated risk of dementia death warrants testing in studies with measures of disease incidence. 


\section{References}

1. Global Observatory for Ageing and Dementia Care. World Alzheimer Report 2015. London: Alzheimer's Disease International, 2015.

2. Daviglus ML, Plassman BL, Pirzada A, et al. Risk factors and preventive interventions for Alzheimer disease: state of the science. Arch Neurol 2011; 68:1185-90.

3. Durazzo TC, Mattsson N, Weiner MW. Smoking and increased Alzheimer's disease risk: a review of potential mechanisms. Alzheimers Dement 2014; 10:S122-S145.

4. Batty GD, Russ TC, Starr JM, Stamatakis E, Kivimaki M. Modifiable cardiovascular disease risk factors as predictors of dementia death: pooling of ten general population-based cohort studies. J Negat Results Biomed 2014; 13:8.

5. Russ TC, Hamer M, Stamatakis E, Starr JM, Batty GD, Kivimaki M. Does the Framingham cardiovascular disease risk score also have predictive utility for dementia death? An individual participant meta-analysis of 11,887 men and women. Atherosclerosis 2013; 228:256-8.

6. Russ TC, Stamatakis E, Hamer M, Starr JM, Kivimaki M, Batty GD. Socioeconomic status as a risk factor for dementia death: individual participant meta-analysis of 86508 men and women from the UK. Br J Psychiatry 2013; 203:10-7.

7. Russ TC, Kivimaki M, Starr JM, Stamatakis E, Batty GD. Height in relation to dementia death: individual participant meta-analysis of $18 \mathrm{UK}$ prospective cohort studies. $\mathrm{Br} \mathrm{J}$ Psychiatry 2014; 205:348-54.

8. Feyerabend C, Russell MA. A rapid gas-liquid chromatographic method for the determination of cotinine and nicotine in biological fluids. J Pharm Pharmacol 1990; 42:450-2.

9. Jarvis MJ, Primatesta P, Erens B, Feyerabend C, Bryant A. Measuring nicotine intake in population surveys: comparability of saliva cotinine and plasma cotinine estimates. Nicotine Tob Res 2003; 5:349-55.

10. Russ TC, Batty GD, Starr JM. Cognitive and behavioural predictors of survival in Alzheimer disease: results from a sample of treated patients in a tertiary-referral memory clinic. Int $\mathrm{J}$ Geriatr Psychiatry 2012; 27:844-53.

11. Cox DR. Regression models and life-tables. J R Stat Soc [Ser B] 1972; 34:187-220.

12. van der Linde RM, Dening T, Stephan BC, Prina AM, Evans E, Brayne C. Longitudinal course of behavioural and psychological symptoms of dementia: systematic review. $\mathrm{Br} \mathrm{J}$ Psychiatry 2016; 209:366-77.

13. Chen R, Wilson $\mathrm{K}$, Chen $\mathrm{Y}$, et al. Association between environmental tobacco smoke exposure and dementia syndromes. Occup Environ Med 2013; 70:63-9.

14. Llewellyn DJ, Lang IA, Langa KM, Naughton F, Matthews FE. Exposure to secondhand smoke and cognitive impairment in non-smokers: national cross sectional study with cotinine measurement. BMJ 2009; 338:b462.

15. Barnoya J, Glantz SA. Cardiovascular effects of secondhand smoke: nearly as large as smoking. Circulation 2005; 111:2684-98.

16. Koizumi K, Wang G, Park L. Endothelial Dysfunction and Amyloid-beta-Induced Neurovascular Alterations. Cell Mol Neurobiol 2016; 36:155-65. 
Table 1. Association of plasma and salivary cotinine with death from dementia: pooling of 14 cohort studies

\begin{tabular}{|c|c|c|c|c|c|c|c|c|}
\hline \multirow{2}{*}{$\begin{array}{l}\text { Smoking status } \\
\text { (Cotinine, ng/ml) }\end{array}$} & \multicolumn{4}{|c|}{ Plasma cotinine } & \multicolumn{4}{|c|}{ Salivary cotinine } \\
\hline & $\begin{array}{c}\text { Number } \\
\text { at risk }\end{array}$ & $\begin{array}{c}\text { Dementia } \\
\text { cases }\end{array}$ & \multicolumn{2}{|c|}{ Hazard Ratio (95\% CI) } & $\begin{array}{c}\text { Number } \\
\text { at risk }\end{array}$ & $\begin{array}{c}\text { Dementia } \\
\text { cases }\end{array}$ & \multicolumn{2}{|c|}{ Hazard Ratio (95\% CI) } \\
\hline & 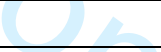 & & & & & & & \\
\hline $\begin{array}{l}\text { Passive smokers } \\
(1.1-15.0)\end{array}$ & 2347 & 16 & $\begin{array}{c}1.19 \\
(0.69,2.06)\end{array}$ & $\begin{array}{c}1.07 \\
(0.62,1.86)\end{array}$ & 4223 & 22 & $\begin{array}{c}1.26 \\
(0.79,2.01)\end{array}$ & $\begin{array}{c}1.23 \\
(0.77,1.97)\end{array}$ \\
\hline $\begin{array}{l}\text { Active smokers, high } \\
\text { intensity }(>200.0)\end{array}$ & 2816 & 14 & $\begin{array}{c}1.84 \\
(1.02,3.33)\end{array}$ & $\begin{array}{c}1.79 \\
(0.98,3.27)\end{array}$ & 5535 & 11 & $\begin{array}{c}1.19 \\
(0.63,2.25)\end{array}$ & $\begin{array}{c}1.14 \\
(0.60,2.17)\end{array}$ \\
\hline & & & 8 & 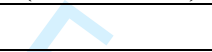 & & & & \\
\hline P-value for trend & - & - & 0.02 & 0.03 & - & - & 0.27 & 0.35 \\
\hline & & & & & & & & \\
\hline $\begin{array}{l}\text { Per 1 standard } \\
\text { deviation higher } \\
\text { cotinine }^{\mathrm{a}}\end{array}$ & 15130 & 119 & $\begin{array}{c}1.31 \\
(1.07,1.61)\end{array}$ & $\begin{array}{c}1.29 \\
(1.05,1.59)\end{array}$ & 33032 & 135 & $\begin{array}{c}1.12 \\
(0.91,1.38)\end{array}$ & $\begin{array}{c}1.10 \\
(0.89,1.36)\end{array}$ \\
\hline
\end{tabular}

Model 1 - Hazard ratios are adjusted for age, age squared, sex, survey year.

Model 2 - Hazard ratios are adjusted for age, age squared, sex, survey year, socioeconomic status, frequency of alcohol consumption, longstanding illness.

${ }^{\mathrm{a}}$ Cotinine values were transformed to $\log ($ cotinine +0.5$)$ for this analysis to remove skewness 
Supplemental Table 1. Association of plasma and salivary cotinine with death from dementia (excluding deaths in the first 5 years of followup): pooling of 14 cohort studies

\begin{tabular}{|c|c|c|c|c|c|c|c|c|}
\hline \multirow{3}{*}{$\begin{array}{l}\text { Smoking status } \\
\text { (Cotinine, ng/ml) }\end{array}$} & \multicolumn{4}{|c|}{ Plasma cotinine } & \multicolumn{4}{|c|}{ Salivary cotinine } \\
\hline & \multirow{2}{*}{$\begin{array}{l}\text { Number } \\
\text { at risk }\end{array}$} & \multirow{2}{*}{\begin{tabular}{|c|}
$\begin{array}{c}\text { Dementia } \\
\text { cases }\end{array}$ \\
\end{tabular}} & \multicolumn{2}{|c|}{ Hazard Ratio (95\% CI) } & \multirow{2}{*}{$\begin{array}{c}\text { Number } \\
\text { at risk }\end{array}$} & \multirow{2}{*}{$\begin{array}{c}\text { Dementia } \\
\text { cases }\end{array}$} & \multicolumn{2}{|c|}{ Hazard Ratio (95\% CI) } \\
\hline & & & Model 1 & Model 2 & & & Model 1 & Model 2 \\
\hline & 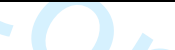 & & & & & & & \\
\hline $\begin{array}{l}\text { Non-smokers } \\
(0-1.0)\end{array}$ & 7924 & 58 & 1.0 (ref) & 1.0 (ref) & 14052 & 68 & 1.0 (ref) & 1.0 (ref) \\
\hline $\begin{array}{l}\text { Passive smokers } \\
(1.1-15.0)\end{array}$ & 2197 & 13 & $\begin{array}{c}1.29 \\
(0.70,2.37)\end{array}$ & $\begin{array}{c}1.17 \\
(0.63,2.16)\end{array}$ & 3502 & 15 & $\begin{array}{c}1.21 \\
(0.69,2.12)\end{array}$ & $\begin{array}{c}1.19 \\
(0.68,2.10)\end{array}$ \\
\hline $\begin{array}{l}\text { Active smokers, low } \\
\text { intensity (15.1-200.0) }\end{array}$ & 1267 & 12 & $\begin{array}{c}2.16 \\
(1.15,4.04) \\
\end{array}$ & $\begin{array}{c}2.07 \\
(1.10,3.88) \\
\end{array}$ & 1522 & 8 & $\begin{array}{c}1.81 \\
(0.87,3.77) \\
\end{array}$ & $\begin{array}{c}1.79 \\
(0.85,3.75) \\
\end{array}$ \\
\hline \multirow[t]{2}{*}{$\begin{array}{l}\text { Active smokers, high } \\
\text { intensity }(>200.0)\end{array}$} & 2602 & 12 & $\begin{array}{c}2.13 \\
(1.11,4.08) \\
\end{array}$ & $\begin{array}{c}2.17 \\
(1.12,4.19) \\
\end{array}$ & 4093 & 7 & $\begin{array}{c}1.02 \\
(0.46,2.25) \\
\end{array}$ & $\begin{array}{c}1.00 \\
(0.45,2.20) \\
\end{array}$ \\
\hline & & & & +8 & & & & \\
\hline P-value for trend & - & - & 0.004 & 0.005 & - & - & 0.41 & 0.47 \\
\hline $\begin{array}{l}\text { Per } 1 \text { standard } \\
\text { deviation higher } \\
\text { cotinine }^{\mathrm{a}}\end{array}$ & 13990 & 95 & $\begin{array}{c}1.43 \\
(1.14,1.78)\end{array}$ & $\begin{array}{c}1.42 \\
(1.14,1.78)\end{array}$ & 23169 & 98 & $\begin{array}{c}1.11 \\
(0.87,1.42)\end{array}$ & $\begin{array}{c}1.09 \\
(0.85,1.40)\end{array}$ \\
\hline & & & & & & & & \\
\hline
\end{tabular}

Model 1 - Hazard ratios are adjusted for age, age squared, sex, survey year.

Model 2 - Hazard ratios are adjusted for age, age squared, sex, survey year, socioeconomic status, frequency of alcohol consumption, longstanding illness.

${ }^{\mathrm{a}}$ Cotinine values were transformed to $\log ($ cotinine +0.5$)$ for this analysis to remove skewness 